\title{
A Printed Microstrip Antenna for RADAR Communication
}

\author{
Bipa Datta ${ }^{1}$, Arnab Das ${ }^{2}$, Samiran Chatterjee ${ }^{3}$, Moumita Mukherjee ${ }^{4}$, Santosh \\ Kumar Chowdhury ${ }^{5}$ \\ ${ }^{1,2,3}$ ECE Department, West Bengal University of Technology, Brainware Group of Institutions, Barasat, West \\ Bengal, India \\ ${ }^{4}$ Centre for Millimeter wave Semiconductor Devices and Systems (Centre of DRDO, Govt. of India \& University \\ of Calcutta), University of Calcutta, West Bengal, India \\ ${ }^{5}$ ECE Department, West Bengal University of Technology, JIS College of Engineering, Phase-III, Block-A5, \\ Kalyani, Nadia, West Bengal, India
}

\begin{abstract}
A single layer, single feed compact slotted patch antenna is thoroughly simulated in this paper. Resonant frequency has been reduced drastically by cutting two different slots. The first one is the combinations of two triangular and another rectangular slot at the upper right corner and rest is bilateral triangle at the lower left corner from the conventional microstrip patch antenna. Simulated antenna size has been reduced by $48.11 \%$ with an increased frequency ratio when compared to a Conventional microstrip patch antenna.
\end{abstract}

Keywords-Bandwidth, Compact, Patch, Resonant frequency, Slot

\section{INTRODUCTION}

Modern wireless devices are required to provide a myriad of services, leading to increased Demands for microwave communications that support multiple applications. In addition to this multi-functionality, users expect compactness of their gadgets, in which the antennas and batteries are the most restrictive components that hinder the accomplishment of size requirements. In recent years demand, a small and light weight compact multi-resonant microstrip antenna which supports the high mobility, necessity for a wireless telecommunication device and for high resolution mapping, for radar communication [1-6]. Due to many reasons, mainly because there are various wireless communication systems and many telecommunication operators using various frequencies, multiband characteristic is more desirable than having one antenna for each frequency band. Most effective technique is cutting slot in proper position on the microstrip patch. In this paper includes cutting two different slots on which the first one is the combinations of two triangular and another rectangular slot at the upper right corner and rest is bilateral triangle at the lower left corner from the conventional microstrip patch antenna, to increase the return loss and gain-bandwidth performance of the simulated antenna (Fig 2). To reduce the size of the antenna substrates are chosen with higher value of dielectric constant [7-10]. Our aim is to reduce the size of the antenna as well as increase the operating bandwidth. The proposed antenna (substrate with $\varepsilon_{r}=$ 4.4) has a gain of $3.98 \mathrm{dBi}$ and presents a size reduction of $48.11 \%$ when compared to a conventional microstrip patch $(10 \mathrm{~mm} \times 6 \mathrm{~mm})$. The simulation has been carried out by IE3D [11] software which uses the MOM method. Due to the small size, low cost and low weight this antenna is a good entrant for the application of XBand microwave communication and Ku-Band RADAR communication.

The $\mathrm{X}$ band and $\mathrm{Ku}$-Band defined by an IEEE standard for radio waves and radar engineering with frequencies that ranges from 8.0 to $12.0 \mathrm{GHz}$ and 12.0 to $18.0 \mathrm{GHz}$ respectively. The $\mathrm{X}$ band is used for short range tracking, missile guidance, marine, radar and airbone intercept. Especially it is used for radar communication ranges roughly from $8.29 \mathrm{GHz}$ to $11.4 \mathrm{GHz}$. The Ku band is used for high resolution mapping and satellite altimetry. Especially, $\mathrm{Ku}$ Band is used for tracking the satellite within the ranges roughly from $12.87 \mathrm{GHz}$ to $14.43 \mathrm{GHz}$.

\section{ANTENNA DESIGN}

The configuration of the conventional printed antenna is shown in Figure 1 with $\mathrm{L}=6 \mathrm{~mm}, \mathrm{~W}=10 \mathrm{~mm}$, substrate (PTFE) thickness $\mathrm{h}=1.6 \mathrm{~mm}$, dielectric constant $\varepsilon_{\mathrm{r}}=4.4$. Coaxial probe-feed (radius $=0.5 \mathrm{~mm}$ ) is located at $\mathrm{W} / 2$ and $\mathrm{L} / 3$. Assuming practical patch width $\mathrm{W}=10 \mathrm{~mm}$ for efficient radiation and using the equation [6],

$\mathrm{f}_{\mathrm{r}}=\frac{\mathrm{c}}{2 \mathrm{~W}} \times \sqrt{\frac{2}{\left(1+\varepsilon_{\mathrm{r}}\right)}}$

Where, $\mathrm{c}=$ velocity of light in free space. Using the following equation [9] we determined the practical length $\mathrm{L}$ $(=6 \mathrm{~mm})$.

$L=\mathrm{L}_{\mathrm{eff}}-2 \Delta \mathrm{L}$ 


$$
\begin{gathered}
\text { where, } \frac{\Delta L}{h}=\left[0.412 \times \frac{\left(\varepsilon_{\text {reff }}+0.3\right) \times(\mathrm{W} / \mathrm{h}+0.264)}{\left(\varepsilon_{\text {reff }}-0.258\right) \times(\mathrm{W} / \mathrm{h}+0.8)}\right] \\
\varepsilon_{\text {reff }}=\left[\left(\frac{\varepsilon_{\mathrm{r}}+1}{2}\right)+\frac{\varepsilon_{\mathrm{r}}-1}{\left(2 \times \sqrt{\left(1+12 \times \frac{h}{W}\right)}\right)}\right] \\
\text { And } L_{\text {eff }}=\left[\frac{c}{2 \times f_{r} \times \sqrt{\epsilon_{e f f}}}\right]
\end{gathered}
$$

Where, $\mathrm{L}_{\text {eff }}=$ Effective length of the patch, $\Delta \mathrm{L} / \mathrm{h}=$ Normalized extension of the patch length, $\varepsilon_{\text {reff }}=$ Effective Dielectric constant.

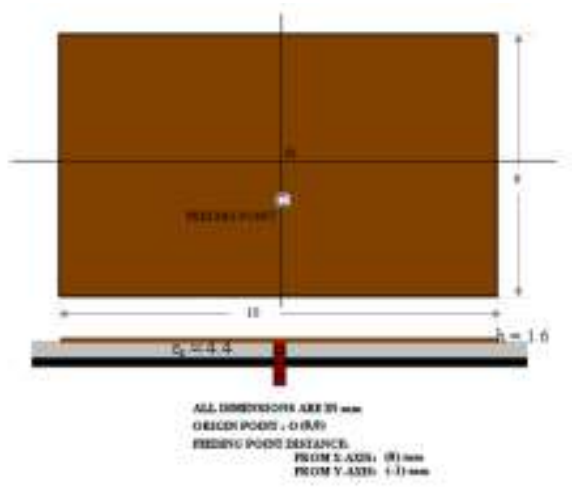

Figure 1: Conventional Antenna configuration

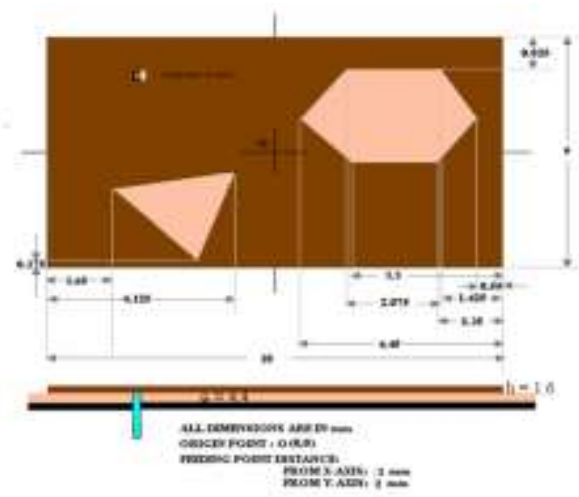

Figure 2: Simulated Antenna configuration

Figure 2 shows the configuration of simulated printed antenna designed with similar PTFE substrate. Cutting two different slots on which the first one is the combinations of two triangular and another rectangular slot at the upper right corner and rest is bilateral triangle at the lower left corner and the location of coaxial probe-feed (radius $=0.5 \mathrm{~mm}$ ) are shown in the figure 2 .

\section{RESULTS AND DISCUSSION}

Simulated (using IE3D [11]) results of return loss in conventional and simulated antenna structures are shown in Figure 3-4. A significant improvement of frequency reduction is achieved in simulated antenna with respect to the conventional antenna structure.

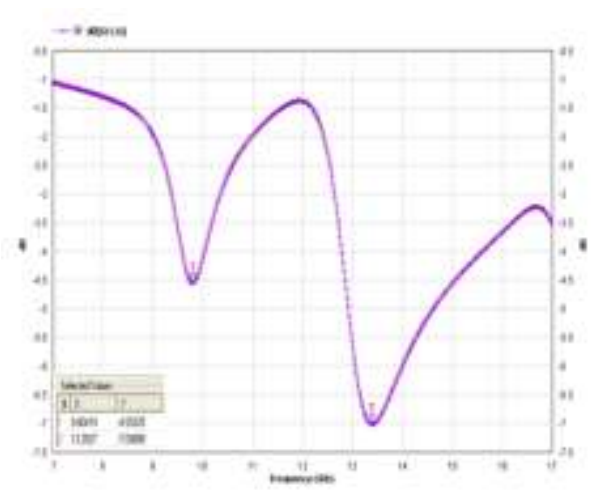

Figure 3: Return Loss vs. Frequency (Conventional Antenna)

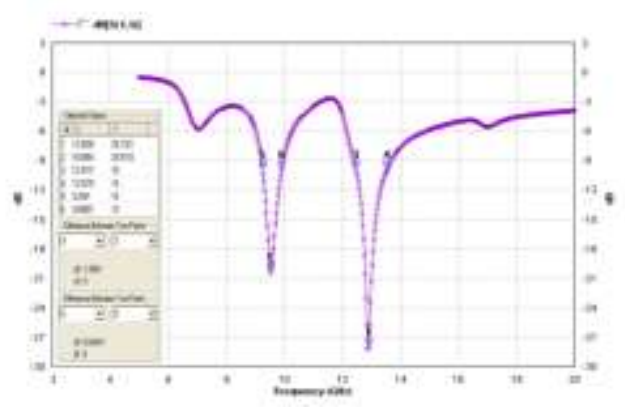

Figure 4: Return Loss vs. Frequency (Slotted Antenna)

In the conventional antenna return loss of about $-7.01 \mathrm{~dB}$ is obtained at $13.39 \mathrm{GHz}$. Comparing fig. 3 and fig.4 it may be observed that for the conventional antenna (fig.3), there is practically no resonant frequency at around $9.54 \mathrm{GHz}$ with a return loss of around $-6 \mathrm{~dB}$. For the simulated antenna there is a resonant frequency at around $9.54 \mathrm{GHz}$ where the return loss is as high as $-20.51 \mathrm{~dB}$.

Due to the presence of slots in simulated antenna resonant frequency operation is obtained with large values of frequency ratio. The first and second resonant frequency is obtained at $f_{1}=9.54 \mathrm{GHz}$ with return loss of about $\quad-20.51 \mathrm{~dB}$ and at $\mathrm{f}_{2}=12.90 \mathrm{GHz}$ with return losses $-28.13 \mathrm{~dB}$ respectively.

Corresponding 10dB band width obtained for Antenna 2 at f1, f2 are $642.41 \mathrm{MHz}$ and $1.05 \mathrm{GHz}$ respectively. The simulated E plane and H-plane radiation patterns are shown in fig 5-12. The simulated 2D E plane radiation pattern of simulated antenna for $9.54 \mathrm{GHz}$ is shown in figure 5 . 


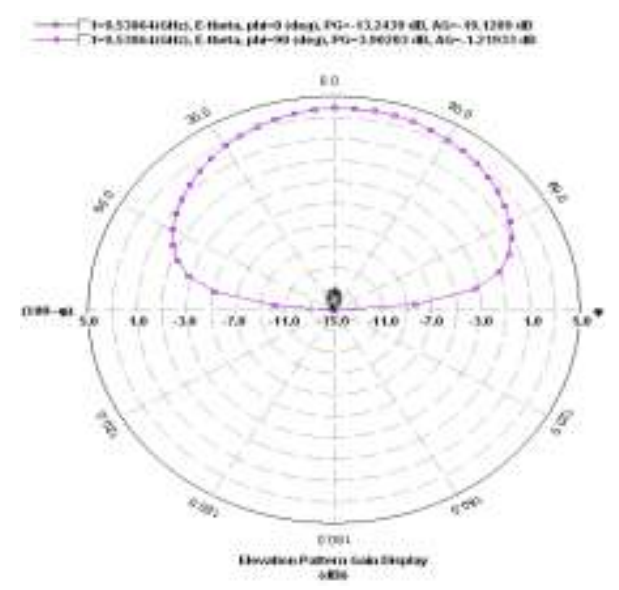

Figure 5: E-Plane (2D View) Radiation Pattern for slotted Antenna at $9.54 \mathrm{GHz}$

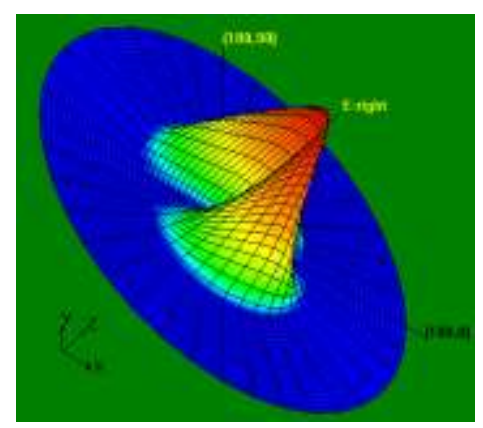

Figure 7: E-Plane (3D View) Radiation Pattern for slotted antenna at $9.54 \mathrm{GHz}$

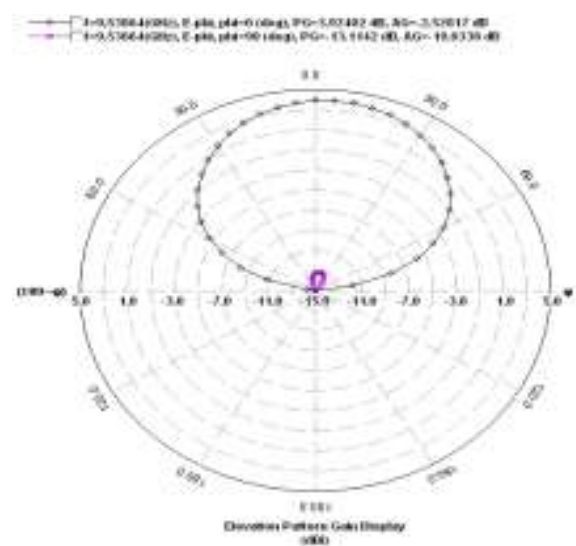

Figure 6: H-Plane (2D View) diation Pattern

for slotted Antenna at $9.54 \mathrm{GHz}$

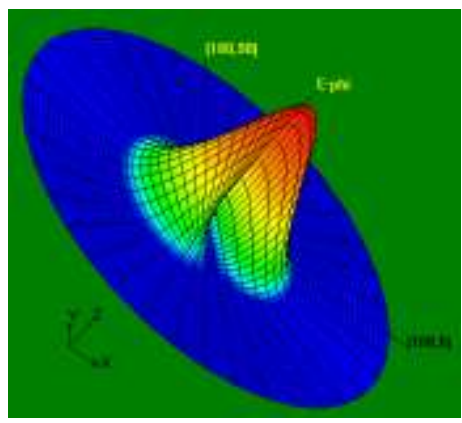

Figure 8: H-Plane (3D View) Radiation Pattern for slotted antenna at $9.54 \mathrm{GHz}$

The simulated 2D H plane radiation pattern of simulated antenna for $9.54 \mathrm{GHz}$ is shown in fig 6 . The simulated E plane radiation pattern (3D-view) of Slotted Antenna for $9.54 \mathrm{GHz}$ is shown in fig 7 . The simulated $\mathrm{H}$ plane radiation pattern (3D-view) of Slotted Antenna for $9.54 \mathrm{GHz}$ is shown in figure 8 .

The simulated $\mathrm{E}$ plane radiation pattern of slotted antenna for $12.90 \mathrm{GHz}$ is shown in figure 9 . The simulated $\mathrm{H}$ plane radiation pattern of slotted antenna for $12.90 \mathrm{GHz}$ is shown in fig 10 .

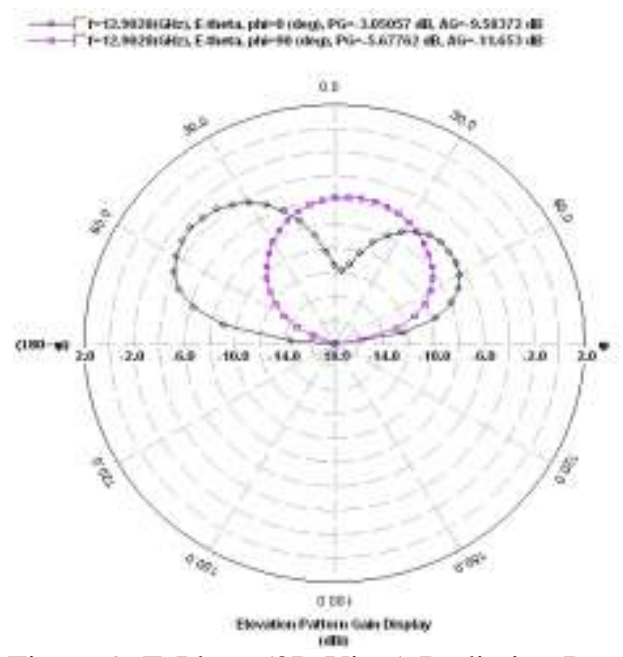

Figure 9: E-Plane (2D View) Radiation Pattern for slotted antenna at $12.90 \mathrm{GHz}$

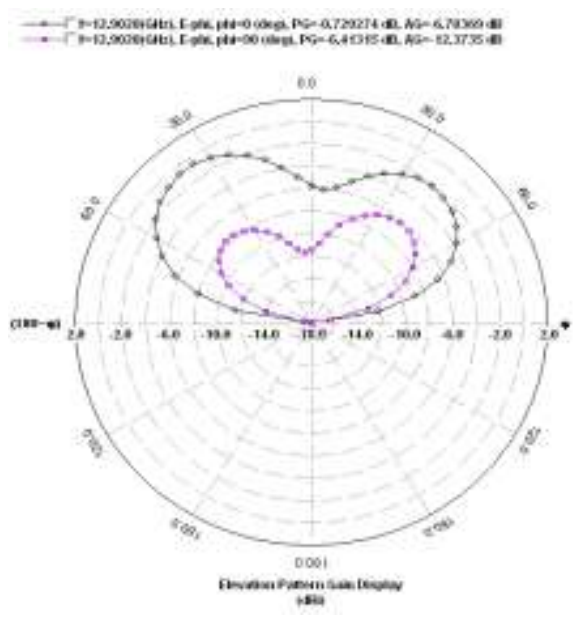

Figure 10: H-Plane (2D View) Radiation Pattern for slotted antenna at $12.90 \mathrm{GHz}$ 


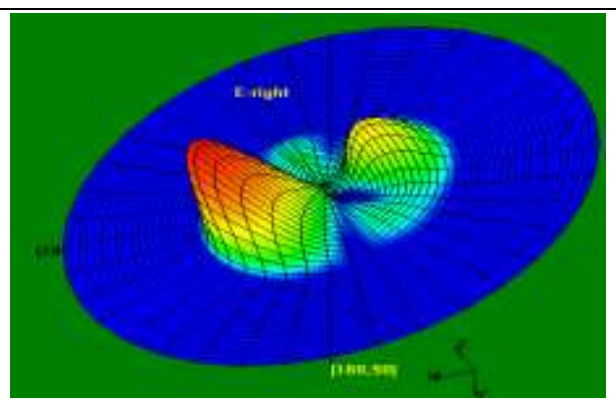

Figure 11: E-Plane (3D View) Radiation Pattern for slotted antenna at $12.90 \mathrm{GHz}$

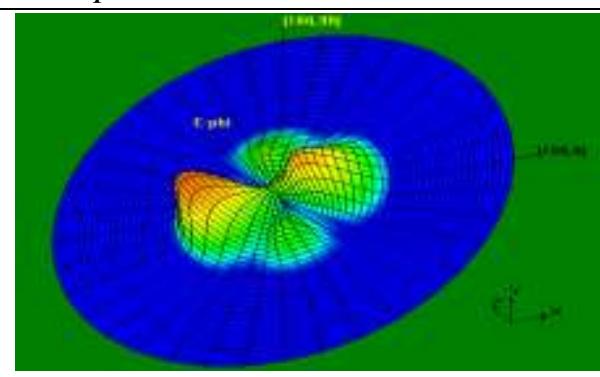

Figure 12: H-Plane (3D) Radiation Pattern for slotted antenna at $12.90 \mathrm{GHz}$

The simulated E plane radiation pattern (3D-view) of Slotted Antenna for $12.90 \mathrm{GHz}$ is shown in fig 11 . The simulated $\mathrm{H}$ plane radiation pattern (3D-view) of Slotted Antenna for $12.90 \mathrm{GHz}$ is shown in fig 12.

All the simulated results are summarized in the following Table1 and Table2.

TABLE I:

SIMULATED RESULTS FOR ANTENNA 1 AND 2
TABLE II:

SIMULATED RESULTS FOR ANTENNA 1 AND 2

\begin{tabular}{|c|c|c|c|c|}
\hline $\begin{array}{c}\text { ANTENNA } \\
\text { STRUCTUR } \\
\text { E }\end{array}$ & $\begin{array}{c}\text { RESONAN } \\
\text { T }\end{array}$ & $\begin{array}{c}\text { FREQUEN } \\
\text { CY } \\
\text { RREQUEN } \\
\text { RATIO }\end{array}$ & $\begin{array}{c}\text { 3 DB } \\
\text { BEAM- } \\
\text { WIDT } \\
\text { CY }\end{array}$ & $\begin{array}{c}\text { ABSOLU } \\
\text { TE GAIN } \\
\text { (DBI) }\end{array}$ \\
\hline Conventional & $\mathrm{f}_{1}=13.39$ & & $\mathrm{NA}$ & \\
\hline Slotted & $\mathrm{f}_{1}=9.54$ & \multirow{2}{*}{$\mathrm{f}_{2} / \mathrm{f}_{1}=1.352$} & $165.47^{0}$ & 3.980 \\
\cline { 2 - 4 } & $\mathrm{f}_{2}=12.90$ & & $144.27^{0}$ & 1.140 \\
\hline
\end{tabular}

\begin{tabular}{|c|l|c|c|}
\hline $\begin{array}{c}\text { ANTENNA } \\
\text { STRUCTURE }\end{array}$ & $\begin{array}{c}\text { RESONAN } \\
\text { T } \\
\text { FREQUEN } \\
\text { CY }\left(\mathbf{G H}_{\mathbf{Z}}\right)\end{array}$ & $\begin{array}{c}\text { RETU } \\
\text { RN } \\
\text { LOSS } \\
(\mathbf{D B})\end{array}$ & $\begin{array}{c}\text { 10 DB } \\
\text { BAND } \\
\text { WIDT } \\
\mathbf{H} \\
\left(\mathbf{G H}_{\mathbf{Z}}\right)\end{array}$ \\
\hline Conventional & $\mathrm{f}_{1}=13.39$ & -7.01 & NA \\
\hline Slotted & $\mathrm{f}_{1}=9.54$ & -20.51 & 0.6424 \\
\cline { 2 - 4 } & $\mathrm{f}_{2}=12.90$ & -28.13 & 1.0541 \\
\hline
\end{tabular}

IV.

\section{CONCLUSION}

Theoretical investigations of the single layer single feed multi-resonant microstrip printed antennas have been carried out using Method of Moment based software IE3D. Introducing slots at the edge of the patch size reduction of about $48.11 \%$ has been achieved. The $3 \mathrm{~dB}$ beam-width of the radiation pattern $165.47^{\circ}$ (for $\mathrm{f}_{1}$ ) and $144.27^{\circ}$ (for $\mathrm{f}_{2}$ ) which is sufficiently broad beam for the applications for which it is intended. The resonant frequency of slotted antenna presented in the paper for a particular location of feed point $(-3 \mathrm{~mm}, 2 \mathrm{~mm})$ considering the centre as the origin was quite large as is evident from table1. Alteration of the location of the feed point results in narrower $10 \mathrm{~dB}$ bandwidth and less sharp resonances.

\section{Acknowledgements}

S. K. Chowdhury gratefully acknowledged, the financial support for this work provided by AICTE (India) in the form of a project entitled "DEVELOPMENT OF COMPACT, BROADBAND AND EFFICIENT PATCH ANTENNAS FOR MOBILE COMMUNICATION". M. Mukherjee wishes to acknowledge Defense Research and Development Organization (DRDO, Ministry of Defense), Govt. of India for their financial assistance.

\section{REFERENCES}

[1] I.Sarkar, P.P.Sarkar, S.K.Chowdhury “A New Compact Printed Antenna for Mobile Communication”, 2009 Loughborough Antennas \& Propagation Conference, 16-17 November 2009, pp 109-112.

[2] S. Chatterjee, U. Chakraborty, I.Sarkar, S. K. Chowdhury, and P.P.Sarkar, "A Compact Microstrip Antenna for Mobile Communication", IEEE annual conference. Paper ID: 510

[3] J.-W. Wu, H.-M. Hsiao, J.-H. Lu and S.-H. Chang, "Dual broadband design of rectangular slot antenna for 2.4 and 5 GHz wireless communication", IEE Electron. Lett. Vol. 40 No. 23, 11 th November 2004.

[4] U. Chakraborty, S. Chatterjee, S. K. Chowdhury, and P. P. Sarkar, "A comact microstrip patch antenna for wireless communication," Progress In Electromagnetics Research $\quad$ C, Vol. 18, 211-220, 2011 http://www.jpier.org/pierc/pier.php?paper=10101205

[5] Rohit K. Raj, Monoj Joseph, C.K. Anandan, K. Vasudevan, P. Mohanan, “ A New Compact Microstrip-Fed Dual-Band Coplaner Antenna for WLAN Applications”, IEEE Trans. Antennas Propag., Vol. 54, No. 12, December 2006, pp 3755-3762.

[6] Zhijun Zhang, Magdy F. Iskander, Jean-Christophe Langer, and Jim Mathews, "Dual-Band WLAN Dipole Antenna Using an Internal Matching Circuit", IEEE Trans. Antennas and Propag.,VOL. 53, NO. 5, May 2005, pp 1813-1818.

[7] J. -Y. Jan and L. -C. Tseng, " Small planar monopole Antenna with a shorted parasitic inverted-L wire for Wireless communications in the 2.4, 5.2 and 5.8 GHz. bands", IEEE Trans. Antennas and Propag., VOL. 52, NO. 7, July 2004, pp -1903-1905.

[8] Samiran Chatterjee, Joydeep Paul, Kalyanbrata Ghosh, P. P. Sarkar and S. K. Chowdhury "A Printed Patch Antenna for Mobile Communication", Convergence of Optics and Electronics conference, 2011, Paper ID: 15, pp 102-107

[9] C. A. Balanis, "Advanced Engineering Electromagnetics”, John Wiley \& Sons., New York, 1989.

[10] Bipa Datta, Arnab Das, Samiran Chatterjee, Bipadtaran Sinhamahapatra, Supriya Jana, Moumita Mukherjee, Santosh Kumar Chowdhury, "Design of Compact Patch Antenna for Multi-Band Microwave Communication", National Conference on Sustainable Development through Innovative Research in Science and Technology (Extended Abstracts), Paper ID: 115, pp 155, 2012

[11] Zeland Software Inc. IE3D: MoM-Based EM Simulator. Web: http://www.zeland.com/ 